\title{
On the Softening Design of Living Environment Hard Factors: A Case Study of Yu Yuan Residential Quarter
}

\author{
Jie Shen ${ }^{1, a^{*}}, \mathrm{Ge} \mathrm{Ma}^{2, \mathrm{~b}}$ \\ ${ }^{1}$ School of Urban Construction, Wuhan University of Science and Technology, Wuhan, China \\ ${ }^{2}$ Han Jia Design Group Co., Ltd., Hangzhou, China \\ a'Sabrina302@163.com, b675493824@qq.com
}

Keywords: Hard landscape, ecology, design, living environment

Abstract: Hard landscape factors have almost penetrated into every corner of living environment, thus occupying a significant position in residential landscape design. The ecosystem-based softening design of landscape hard factors is conducive to break away from the narrow scope of visual aesthetics. Based on the landscape design project of $\mathrm{Yu}$ Yuan residential quarter in Huazhong University of Science and Technology (HUST), this paper aims to discuss landscape design under the guidance of ecology theories during engineering practice with an overall consideration of the extent and scope of its impacts on surrounding ecology.

\section{Introduction}

Located in the Guanshan village of High-Tech Development Zone in East Lake, Yu Yuan teachers residential quarter in HUST has a floor area of more than $200 \mathrm{mu}$ (13.33 hectares) and a total construction area of 309,589 square meters, which is part of the environmental control zone of Wuhan East Lake Scenic Area. The building group is arranged with a sequentially increasing elevation from east to west, which helps to guide summer wind and block winter cold air. In residential landscape design, changes to the original topography should be minimized and the original natural features should be respected so as to achieve the functioning of nature as much as possible, minimize the environmental impacts of new design and help to improve ecological conditions[1]. First, the framework of land use should be determined roughly and the pattern of roads, sewers and catchment area identified. Meanwhile, hard factors should be designed at ecologically insensitive areas or the areas producing the minimal environmental impacts in order to reduce landscape resistance, eliminate adverse environmental effects caused by road and venues, ensure the smooth proceeding of material flow, energy flow and information flow and preserve biological diversity.

\section{Surrounding Environment of Yu Yuan residential quarter and Its Assessment}

HUST is bordered by Yujia Mountain to the north. With an area of 1.89 square kilometers and an elevation of 149.4 meters, Yujia Mountain is the highest peak in the city of Wuhan, connecting such natural forests as Forest Park, Tuan Hill and Nanwang Hill. By means of this ecological network, the 73-square-kilometer East Lake Scenic Area, the habitat for more than 50 kinds of animals, brings enormous vitality to HUST, turning it into a place with the most abundant species in Wuhan.

However, the 200-mu Yu Yuan residential quarter, which was put into construction in 2004, stands in between the campus and Yujia Mountain. The large-scale land disturbance would not only block the original good ecological linkage, but also weaken the ecological connectivity between campus and wild forest. Thus, at the very beginning of residential landscape design, the principle guided by ecological theory is established in an effort to ensure the normal functioning of soft landscape in ecological service, while striving to eliminate the negative ecological impacts of hard factors. 


\section{Design to Soften Hard Factors}

When studying the relationship between buildings and the land they attached in a broader sense, and reversely considering land and its surrounding environment from the angle of land, the baptism brought by a brand-new concept will be given to us. If our ground is shifted to deliberate the living world with an attitude of life caring, it would be discovered that a little bit of restraint and love will be rewarded enormously by the living world.

\section{Subsided Building Apron to Expand Greenland Benefits}

In architectural design, as some architects are accustomed to applying standard drawings without personal thinking, some irrational customs are prevalent nowadays, represented by the practice of designing 600 to $1000 \mathrm{~mm}$ wide building apron surrounding the perimeter of buildings. The area of building apron usually takes up $1 / 6$ to $1 / 8$ of that of the basement. If this area can be converted into green space on the premise of ensuring its normal function, the green rate of living environment can be invisibly increased by about 3\% to $5 \%$. This is undoubtedly an excellent thing for residential buildings where land is as precious as gold.

If building apron is arranged below the ground and beneath the foundation, some space for growing earthing can be saved, which contributes to expand the green space within residential quarter, but also improve the thermal properties of external walls brought by the softening of surrounding environment. The removal of the gray blunt concrete-made third party contributes to a more intimate relationship between buildings and land (Fig. 1). In addition, due to the small underground temperature changes, the points warehouse seam of the subsided building apron may be eliminated or reduced; meanwhile, its service life can be extended as there is no interference of sun and rain.

\section{Enclosure to Enhance the Permeability of Landscape}

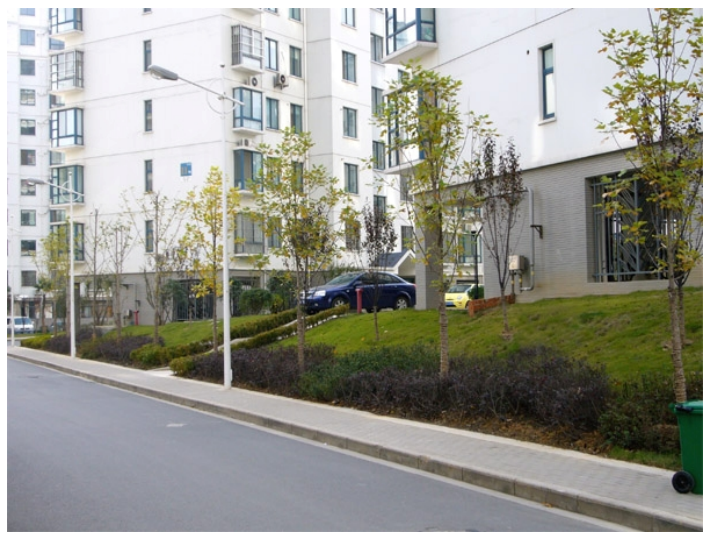

Fig. 1 Subsided Building Apron of Yu Yuan residential quarter

( Source: taken by the author )

Human social system are highly related with earth system, and its interests balance and ethics function are engraved on urban land in the form of enclosure. As the boundary and security facility for specific sites and environment, enclosure not only plays an indispensable role in protecting the security and interests of private space, but also gives the city a landscape style featuring isolation and defense. Besides, from the perspective of ecology, it is also found that such facilities, initially for safeguarding human interests, in realty cut down urban life flow completely, making our human beings become genuine loners that lack of company and communication with other animals.

Thus, how to increase the permeability of walls becomes an important issue in ecological design on the condition that its defense function be guaranteed so as to maintain the interaction of life flow and material flow between campus and Yujia Mountain. Compared with

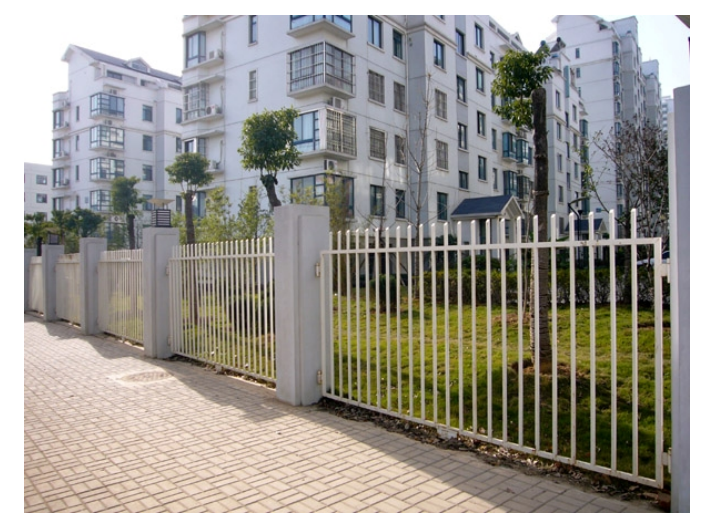

Fig. 2 Enclosure Design of Yu Yuan residential quarter

( Source: taken by the author ) solidly-built walls, flower-shaped iron ones have a better permeability, and in the mean time the hollowed design ensure the freedom and liberation of human vision. But this is still not enough for 
some small animals as the lower threshold of hard and high wall constitutes an obstacle. Thus, from the angle of the living world, to connect the land at the bottom of walls is more important than the emptiness of the upper part (Fig. 2).

\section{Slope to Ensure Land Connectivity}

As it is mentioned above, HUST is against Yujia Mountain on the back and its buildings are laid out gradually along the lowering elevation of the mountain from north to south. If the existing design rules are followed, it seems perfectly justified to convert the slope into platform by excavation and filling. However, it is somewhat a waste of resources for there is sufficiently large building interval. This kind of approach not only increases the construction cost of retaining wall, but also violates the basic principle of ecology on land connectivity. Based on the above understanding, the blunt platform is replaced by the slope with characteristics of softening surrounding environment in the vertical design of $\mathrm{Yu}$ Yuan residential quarter (Fig. 3). Such a design, in ensuring the land connectivity, is also designed to create a diverse and changing environment, wherein

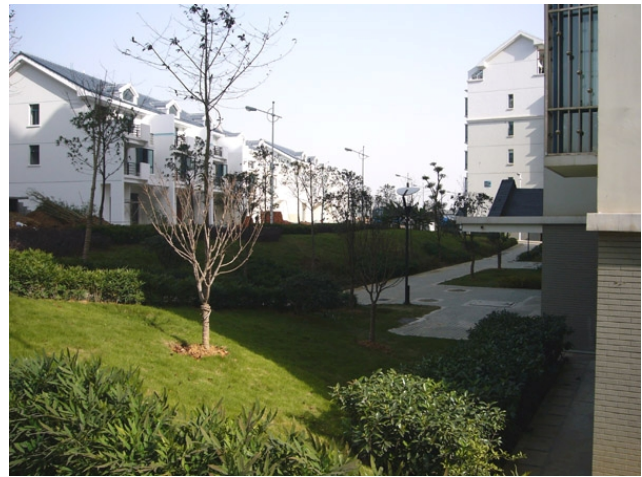

Fig. 3 Slope Design of Yu Yuan residential quarter

( Source: taken bv the author ) the diverse environment is not only the carrier of ensuring biological diversity, but also in line with the form of human's aesthetic needs.

\section{Seepage Ground to Absorb Rain Water}

At present, the common ground subsidence in city has not only created enormous pressure on urban construction and maintenance, but, more importantly, has became an important factor affecting urban ecological health. This is mainly caused by the excessive mining of groundwater resources and the insufficient permeability due to the large urban hard coverage. Through contrast, the latter is found to be more difficult to handle owing to the severe contradiction and opposition between people.

$\mathrm{Yu}$ Yuan residential quarter has a building density of $27.6 \%$ and a green rate of about $35.3 \%$, where major transportation (including square) accounts for $13.3 \%$. According to the Evaluation Standard for Green Building (GB/T50378-2006), all grounds to be hardened within the living area except road and a small amount of other spaces are subject to seepage treatment, where the total engineering quantity is 37,500 square meters, accounting for 28.3 percent of the total land use, including sidewalk, bypassing roads, outdoor parking lot, activity space, etc. The key point of porous pavement is to guarantee the permeability of surface materials and foundation so that the earth can inhale or exhale water and air freely under different external conditions. The pavement surface is porous brick, which is capable of absorbing natural rain water under common circumstances, and meanwhile does not hinder the infiltration of rainwater. Another key factor to be highlighted in terms of porous pavement is the arrangement of cushion; the cushion structure made of discontinuous graded gravels has a higher stability, larger water storage capacity, strong infiltration and certain purification of the infiltration water [2]. Porous pavement ensures the groundwater recharge and purification, decreases surface rainwater runoff, delays residence time, and reduces pressure on urban distribution network, which is thus called the strategy of ecological flood control. In addition, porous pavement ensures the normal circulation of land, adsorbs traffic noise, and plays a part in eliminating trace heavy metals such as lead, zinc, chromium, etc. Meanwhile, it also has protective effects on the living space of plants, animals and micro-organisms at the lower part of soil, helps to reduce surface temperature in summer and mitigate urban heat island effect, and improves the comfortableness and safety of pedestrians. 


\section{Green Roofs with Complete Planting Function}

Early in the twenties, Corbusier has regarded roof garden as one of the five elements constituting new buildings. However, it has not been adequately valued and practiced in modern architecture in China. Yu Yuan residential quarter has an independent one-floor half-underground parking lot, covering an area of 446,0 square meters. Located at the largest concentrated green land, the parking lot is the core space of the residential quarter. To maintain the green land of the space, and also to produce a good ecological environment, it becomes our goal to recreate a space with complete planting function on the roof of the blunt half-underground parking lot.

Under the natural state, it takes 100 to 400 years for vegetation cover to form the $1 \mathrm{~cm}$-thick overburden [3], which shows the preciousness of overburden. Different plants' underground roots require different living space. Studies show that $300 \mathrm{~mm}$-thick overburden can ensure the growth of some herbal plants, $450 \mathrm{~mm}$-thick overburden the survival of some shrub plants, 900mm-thick overburden the growth of some shallow-rooted trees, but it requires more than $1200 \mathrm{~mm}$-thick overburden on the roof to maintain the growth of some deep-rooted trees [4]. Therefore, $1500 \mathrm{~mm}$-thick overburden becomes the basis for the load calculation of underground parking structures.

At the same time, microtopography on the roof garden is built, which can not only create conditions for planting large trees by increasing the depth of overburden locally, but also add some interesting space variations. The semi-exposed portion of the external wall is built into slope, which helps to maintain the slope style of the residential quarter, but also removes the visual

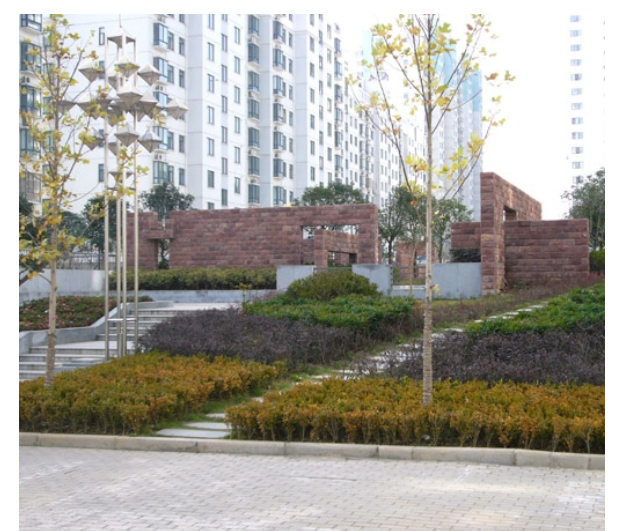

Fig. 4 Square above the Underground Parking Lot of $\mathrm{Yu}$ Yuan residential quarter (Source: taken by the author) existence of the blunt "colossus" (Fig. 4).

\section{Conclusion}

The concept of ecology, though being abstract, is based on some minor problems in architecture. In accordance with theoretical studies on design of hard factors to soften living environment, and based on the residential design practice of Yu Yuan residential quarter in HUST, this paper discusses and studies landscape design from the perspective of ecological theory. Humanity and ecology should not just stay on slogans and propaganda. Thus, following an excessive emphasis on drawing and surface presentation, attention should be paid more to the real living environment because nature is the best design demonstration when problems are encountered.

\section{References}

[1] Yu Kongjian, Toward a new landscape, J. Architecture. 05 (2006) 73.

[2] Ding Yueyuan, Hou Lizhu, Zhang Shuhan, Urban rainwater utilization based on porous pavement, J. Beijing Water, 06 (2006) 1-3.

[3] Lin Xianyi, Design Technologies for Green Buildings, first ed., Architecture and Building Research Institute, 2000.

[4] Huang Jinqi, Design and Construction of Roof Garden, second ed., China Forestry Publishing House, Beijing, 1994. 